\title{
Esfera pública y constitución psíquica en niños marginarizados
}

\author{
Inés Cristina Rosbaco \\ (Escuela de Ciencias de la Educación) \\ (Universidad Nacional de Rosario. \\ CONICET. Argentina)
}

\section{Resumen}

Este trabajo se centra en la necesidad de la apropiación de la esfera pública, de "las Ilaves del código", por parte del sujeto, para su constitución psíquica. Las prácticas docentes al interior de la Escuela tradicional o de escuelas creadas por movimientos sociales, son imprescindibles para la prosecución de la constitución psíquica en dicha esfera.

Los adultos significativos de los niños marginarizados se alejan cada vez más de lo referente a lo público al encontrarse expulsados del sistema productivo.

Es en ésta donde los otros diferentes pueden tensionar al sujeto para que se abra a los objetos de la cultura. Las prácticas docentes tienen la capacidad de ayudar al pasaje de lo familiar a lo público/lo desconocido, a los enigmas por los que sienten curiosidad los niños, necesaria para conocer e interpretar el mundo con un pensamiento crítico, susceptible de transformar-se, en un futuro, la realidad que los oprime. Los docentes pueden posicionarse frente a los niños con una función subjetivante centrada en la devolución de una mirada valorativa como representante del Otro Social. Lo que no es poco en niños a los que con frecuencia los invade una angustia de anonimato.

\section{Palabras clave}

Niños Marginarizados - Psiquismo - La Función Subjetivante de los Docentes - Esfera Pública.

\section{Summary}

This work centers in the necessity of taking over the public spaces and the "code keys" for the subject's psychical constitution. Teacher practices in the traditional public schools and those founded for social movements are essential for the continuation of those spaces.

Significant adults of marginated children are getting further away from the public reference because of being left out of the production system. Is in there where the others can push the subject and direct it to cultural objects. Teacher practices have 
the capacity to help children pass from private to public or unknown spaces; to the enigmas that children are curious, which is fundamental for knowing and understanding the world through a critical thought, susceptible to transform the social reality in the future. Teachers can take a position in front of children having a subjectivity function centered in a view from the other social side. This is very relevant for children who frequently are invaded for the anguish of anonymity.

\section{Key words}

Marginated Children - Psyche - The Teacher Subjectivity Function - Public Sphere.

\section{Introducción}

"Alfabetizar no es sólo aprender a leer y a escribir desde un modelo de escritura homogeinizador, sino posicionarnos frente al mundo, al conocimiento y a las prácticas socio-educativas y políticas para comprenderlo y transformarlo. Darle batalla no sólo a la "pobreza" léxica o de vocabulario sino a la ausencia o minusvaloración de tantas autorías de la palabra-pensamiento. (...)

Sería de enorme importancia que una de las metas de todo proyecto alfabetizador fuese tanto la producción como el análisis progresivo de formas de hablar-pensar-escribir-vivir de distintos grupos, sectores y clases sociales. Contribuir a gestar desde temprana edad la reflexión de esa praxis comunicativa desde una autoría propia, situada (en vez de sitiada) en un aquí y ahora especifico".

-Isabel Requejo-

La cuantiosa concentración de capitales en manos de unos pocos a costa del aumento de bolsones de pobreza, producto de la implementación de políticas al servicio de una economía neoliberal, posee características inéditas en nuestro país.

A tal punto se ha incrementado esta problemática que diversos dispositivos sociales actúan como verdaderos vallados -de todo tipo, entre ellos muros de ladrillo y cemento- destinados a replegar a los pobres a la égida de sus mundos posibles, muy especialmente a las esferas de las denominadas instituciones de encierro caracterizadas por la vigencia de una férrea lógica social/disciplinaria (cárceles, psiquiátricos, escuelas -encierro por turnos cuando no, con doble escolaridad-, etc.). En la actualidad, y en relación a los sectores sociales pobres y/o pauperizados, estos dispositivos desbordan ampliamente sus primigenias funciones de contención deviniendo así en mecanismos destinados expresamente a tratar de garantizar la seguridad 
que supuestamente merece la sociedad en su conjunto, especialmente las demás clases sociales.

Esta nueva conformación del contexto social plantea en la actualidad problemáticas que desafían los conocimientos científicos construidos hasta entonces sobre el desarrollo evolutivo de corte ambientalista-biológico como los sostenidos por algunas teorías de la Psicología respecto a la cronología comprendida en la pubertad-adolescencia (1). Ya no existe forma de contener la miseria y la violencia, que no son innatas, sino el resultado concreto y visible de aquello que "suplimos conseguir".

Coherente con la afirmación de que "la ciencia es el partido de la burguesía", los discursos postmodernos han dado letra para el aggiornamento de diferentes instituciones que guardaban una centralidad monolítica en el denominado Moderno Estado Nación, tal el caso de la educación, la justicia, la salud, etc. Así, estas nuevas lógicas -científico-racionales- se han ido plasmando en las instituciones "modernas" mediante de un proceso de reingeniería sobre los sistemas, organizaciones y establecimientos que las corporizaban y a partir de una adecuación funcional de las leyes y normas que las regulaban. Debido a ello encontramos nuevas pautas y objetivos para una escuela que ya no necesita formar sujetos que respondan a los requerimientos del estatuto de la modernidad, sino que requiere la generación de usuarios con subjetividades bulímicamente consumistas y anoréxicamente pensantes, funcionales a la fluidez que demanda el imperio del mercado (2).

El excedente, aquella franja de la población sobrante en el mundo de la producción y el consumo, ha pasado a constituir el sector expulsado de la esfera de lo público, un sector replegado al mundo de lo privado, mundo en el que sistemáticamente son compelidos a revistar "desprovistos de rostro y voz" (Cazzaniga, 2002). Estos sujetos han sido marginalizados (3), lo que se condice con el afortunado concepto instituyente de "trabajador desocupado".

El sujeto expulsado de los ámbitos de producción, ha pasado a ser un inexistente para el resto del conjunto social, el que sólo recibe acuse de su presencia cuando se sienten amenazados o perturbados a causa de aquellas ocasiones en que los "nadies" tienen conductas delictivas, o bien, cuando sus sufrimientos se vuelven visibles a la mirada de los demás. En este cuadro de situación los piquetes han resultado ser un modo de protesta sumamente efectivo, pues ¿cómo podrían los desocupados hacerse visibles y audibles en sus procesos de reclamo social si no recurriesen a estrategias como la "interrupción el tránsito vehicular"? (4). Estas estrategias -simples y elementales- son las que les otorgan una nueva entidad, entidad que les 
posibilita hacerse visibles, luego de haber perdido su existencia concreta en el mundo de la producción.

Como consecuencia de este nuevo fenómeno social, los niños están constituyendo sus subjetividades de un modo muy peculiar, en el que los referentes adultos de su entorno familiar llevan aproximadamente tres generaciones sin trabajos dignos al estatuto de lo humano. Concomitante a la pérdida de trabajo, se produce en aquéllos un quiebre de ideales que les dificulta a los pequeños una devolución especular de una mirada que ilusoriamente favorezca la unificación del Yo. La transmisión del legado cultural se ha ido diluyendo en estos adultos responsables del pequeño. Debido a esta particularidad, y desde un inicio, los procesos de simbolización de estos niños se verán muy amenazados, resultando por ello relevante esa cuota de "adrenalina" -como gustan denominar algunos autores al exceso de excitación que no encuentra modos simbólicos de tramitarse- que llevan al niño a realizar una descarga pulsional, muchas veces violenta, más relacionada al plano de un trabajo psíquico precario del orden de lo pictogramático (sensaciones arcaicas no mediatizadas por la palabra), que al plano de lo imaginario-simbólico.

La condición de marginalidad ha generado inéditos modos de vida en estos adultos, que conforman una deshilachada trama socio-cultural de la cual son parte constitutiva, de la que resulta un peculiar mundo posible que recibe al niño al nacer.

Sostenemos como enunciado fuerte que la familia no es suficiente para la constitución psíquica, sino que la apropiación por parte del niño de los códigos de la esfera pública completa la estructuración psíquica, sin la cual no es posible dicha estructuración. Como sus padres, cuando los niños son expulsados de la Escuela -institución privilegiada de la esfera pública que la sociedad ofrece al niño como primer acercamiento a dicho espacio-, éstos desestructuran y empobrecen su subjetividad, con el agravante de que se trata de historias subjetivas que ya vienen maltrechas a causa de sufrimientos psíquicos y desligazones representacionales que no permiten la consolidación de procesos de simbolización en virtud de las condiciones en que se encuentran sus adultos significativos que poco pueden donar.

La incidencia de los factores mencionados representa algunos de los más relevantes en relación con los modos en que se están constituyendo las nuevas subjetividades. Dejamos para un próximo texto su profundización. 


\section{Algunas palabras sobre los nuevos sujetos}

Por algo será que los sectores que detentan el Poder se han empecinado en el socavamiento de las subjetividades, tanto de los adultos, de la primera infancia, como así también la de los docentes, principales sostenes estructurantes del niño en la esfera pública. Este inédito fenómeno es extensivo a todas las clases sociales, aunque de manera diferente. Por ejemplo, una queja frecuente en los ámbitos educativos argumenta que los niños están creciendo sin adultos que los acompañen. Convengamos que si el fenómeno es el mismo en clases altas que en los barrios marginales (niños con insuficiente presencia de adultos), los factores que llevan a unos y otros adultos a estar ausentes de la vida de los pequeños no son equiparables.

Coherente con este proceder, los sectores dominantes -reforzados por los medios de comunicación masiva- expresan reiteradamente que lo que se pretende lograr es un hombre libre en sus decisiones a través de la educación (5), con propuestas que sólo han promovido pensamientos cada vez más vacuos, que han alentado, paradójicamente, la heteronomía del pensamiento respecto del Otro Social, haciendo gala de una banalidad sorprendente de pensamiento y afectos.

En el otro extremo, es posible que el Otro ya no sea un Dios o un dictador, sino Internet (Le Breton, 2009) y que el alejamiento cada vez mayor de los niños/adolescentes de los enunciados de ese Otro (Dufour, 2007) estén produciendo nuevas subjetividades, no necesariamente superadoras de las anteriores. Este autor se interroga acerca del "nuevo hombre" que se está gestando, desamarrado del Otro Social, que no reúne ninguno de los rasgos del nuevo hombre con el que soñara alguna vez el Che. A su vez, se interroga por estas nuevas modalidades de conformaciones subjetivas, y dice al respecto:

"Probablemente estemos asistiendo a la invención de la primera generación no engendrada. Si éste fuera el caso, aún se nos escapa la medida de los efectos que pueda tener esta inversión de la antigua deuda simbólica" (Dufour, 2007).

Sospechamos que las políticas que se han implementado en las últimos treinta años aproximadamente, se han propuesto generar un tipo de pensamiento inconsistente -en la era de la fluidez- con sujetos incapaces del menor atisbo de deseo de una transformación social que los liberaría del yugo del cual son sus víctimas, lo que lo torna totalmente funcional a los requerimientos del mercado (Rosbaco, 2008). Los discursos de los adolescentes de las diferentes tribus urbanas son un buen ejemplo del 
escepticismo, impotencia y modos de resistencia que no representan la más mínima amenaza para el sistema actual.

Los adultos de la esfera privada y pública son los responsables de transmitir el legado cultural "en tanto pasado cultural que se hace presente a través de la transmisión que los adultos realizan en la vida cotidiana. Historia de varias generaciones, con sus pautas y normas, que se inscribirán en cada niño y que le permitirá ubicarse y ubicar a los otros en un contexto" (Yanín, 2001).

El sujeto es producto y productor de los modos socio-culturales, los que le permiten el otorgamiento de sentidos al presente, brindándoles de este modo la posibilidad de transformar la realidad social. Sin éstos, el sujeto queda imposibilitado de ordenar su experiencia de vida con los afectos concomitantes en un pasado y mucho menos proyectarse a un futuro porvenir. Su ser queda reducido a un "siendo" que no tiene tiempo, a una mera presencia aferrada a lo real (6), que le permite la supervivencia en un día a día. (Vg.: En ocasión de encontrarse trabajando un grupo de alumnos de la Carrera de Ciencias de la Educación sobre narrativa, mediante un dispositivo grupal con niños marginarizados, éstos se rehusaron a que se les contara cuentos y también a construirlos, diciendo: "No queremos chamullos. Todo es un chamullo").

En dicha oportunidad el coordinador y los observadores participantes tuvieron que recurrir a dibujos y trabajos con otros materiales (plastilina, plastimasa) hasta que los niños, de a poco y apoyados en lo concreto (susceptibles de ser manipulados y más fácil de controlar que la palabra "que se lleva el viento"), comenzaron ellos mismos a introducirse en narrativas autorrefenciales. Esta situación fue interpretada por nosotros, y en función del contexto en el que estos niños vivían, mediante una doble lectura: por un lado, esta conducta de descreimiento en la palabra no dejaba de tener un cariz defensivo pero, por el otro, puede que les resultara mucho más operativo para la supervivencia aferrarse a la realidad concreta, no mediatizada por la palabra (lo imaginario-simbólico), sino por el imperativo de las urgencias vividas.

Nos parece plausible que la entrada al mundo de lo imaginariosimbólico tenga como condición necesaria experiencias de placer que no suelen tener estos niños con cuerpos "socialmente maltratados" y alto grado de sufrimiento. Esto constituye un tema a investigar en función de las repercusiones que este tópico podría tener para arribar a una escucha sin preconceptos. Piera Aulagnier (1979) es categórica al afirmar que si la experiencia de satisfacción produce displacer originará el rechazo, situación que constituye marcas indelebles cuando se producen en los inicios de la vida psíquica. 
Tanto la función de amparo, la de interpretar y donar sentidos a la conducta del bebé -que fundan los rudimentos de la organización de la actividad psíquica-, junto a las funciones de filiación y transmisión de la herencia cultural (Käes, 1986) y la instauración de una legalidad edípica, requieren de adultos responsables por el niño. Se trata de una responsabilidad que no puede delegarse a chicos más grandes o adolescentes. $Y$ mucho menos, concebir que dicho legado se encuentre en la "atmósfera" que rodea el ambiente en el que crece el niño. Discursos éstos que pretenden resistir y cuestionar lo instituido -la escuela-, razón por la cual sólo encuentran en las instituciones modos cristalizados de "saberes vencidos" al servicio de una reproducción cultural que no participa de la formación de subjetividades acordes a las demandas actuales (7).

Acordamos con que la autoridad que otorga la terceridad que encarnaría la Escuela se ha resquebrajado, al igual que las normativas de las organizaciones, pero entonces ¿qué hacer? Orientamos nuestras prácticas a apuntalar estas subjetividades que se han tornado muy vulnerables y fragmentarias, o proponemos, bajo el supuesto de que "todo espacio es subjetivante", otras alternativas "creativas", en espacios altamente fragmentados que pueden producir el efecto contrario al esperado, con el riesgo de promover una mayor desimbolización en nombre de la libre expresión del pensamiento y la creatividad.

Coincidimos con los autores que plantean que todo espacio subjetiva, pero haciendo la salvedad que no todos son igualmente subjetivantes. Los niños/adolescentes de las fabelas, que controlan -armados- el tráfico de drogas y otras maniobras ilegales que circulan en éstas, imponiendo reglas que ellos mismos generan, son niños/adolescentes "sueltos" de la mano de Dios (léase: de la responsabilidad que le cabe al Estado con respecto a la protección de sus ciudadanos). Nadie duda que entre la opción de quedar confrontados a su indefensión y desamparo por parte de quienes debieran prodigarles los materiales para que no tengan que procurarse ellos mismos sus modos de supervivencia, es efectivo el aglutinamiento como modo de relacionarse, que torna a cualquier espacio territorial en protector y subjetivante. Nos preocupa la calidad de estas cualidades y de las "simbolizaciones" que contribuyen a generar modos de relación que rayan en lo aberrante.

Nuestros niños marginarizados ya no visualizan perspectivas de un futuro para ellos. Y esto no ocurre porque sus discursos se sustenten en alguna filosofía de corte agnóstico o escéptico, sino que, por el contrario, sus enunciados se caracterizan por un exacerbado aferramiento a la realidad, de la cual no pueden permitirse un descuido, lo que los inhabilita 
a abrirse a la posibilidad de fantasear/jugar con otros mundos posibles. Sus conductas ponen de manifiesto la sobreexigencia que se realiza al Yo del sujeto al tener que aumentar a grados insospechados la función de autoconservación en detrimento de lo autopreservativo (función del Yo relacionada con la identidad). Y hacen bien, cualquier distracción, como ocurriría en medio de una selva, podría anticiparles la muerte anunciada, porque éste es el modo en que viven sus expectativas de vida. Saben que van a morir jóvenes, y así lo expresan.

A causa de esto, a nuestro parecer, la forma de contribuir al armado del psiquismo en nuestras prácticas profesionales -más allá de que sin trabajo es imposible lograrlo como correspondería- pasa por reforzar la función que los adultos deben asumir como responsables de su constitución, lo que trasciende el cuestionamiento de las funciones de reproducción de un sistema injusto y corrupto que definitivamente no deseamos para ningún niño.

Consideramos pertinente apostar a una relativa transformación de las prácticas docentes, fomentando el trabajo en el aula con la inclusión de modalidades novedosas, introductoras de placer, creativas, de las prácticas de quienes trabajan en educación popular y otras modalidades de educación no formal. Es interesante destacar el número cada vez más significativo de docentes que demandan ayuda para repensar sus prácticas en esta línea de trabajo (8). Esto no quiere decir que sostengamos que el cambio profundo de la Escuela será producto de estas prácticas docentes, solamente queremos afirmar que existen muchas modalidades de encarar los procesos de enseñanza-aprendizaje, modalidades que portan brechas que alientan el placer por la producción infantil, características muy apreciadas para el trabajo docente con niños que han crecido con sufrimientos corporales y psíquicos de consideración. Características que estimamos coadyuvarían en los procesos de construcción de proyectos identificatorios (concepto acuñado por Piera Aulagnier, 1979) guiados por ideales, tan ausentes hoy en día.

Convengamos que la familia y la escuela reproducen modos de relación que han llevado a que los niños se estén constituyendo con subjetividades lábiles, como efecto de la implementación de políticas heredadas que han logrado su cometido. Pero habría que pensar que los modos para que los instituidos se transformen no pasan por brindarle al niño opciones por fuera del sistema, sino, más bien, por incluirlos de manera tal que los adultos referentes de la cultura generen prácticas que propicien un efectivo pensamiento crítico, apuntalados en los referentes de la cultura. Ésta se relaciona como los enunciados y significados al que el sujeto adscribe (Aulagnier, 1979). Consideramos que en gran medida, el fracaso escolar de muchos 
niños marginarizados tiene como una de sus causas relevantes la desestimación de los enunciados de fundamento (9) que circulan en el grupo de pertenencia del niño, a la vez que al encontrarse cada vez más alejados de los códigos de la esfera pública, éstos les resultan incomprensibles al interior de la Escuela, por lo que colisionan los unos con los otros, dejando al niño en medio de un mar de confusión con respecto a lo nuevo.

En relación con sus enunciados, cuyos adultos significativos les han transmitido, los docentes desautorizan las imagos paternas sin proponérselo cuando desmienten los enunciados de fundamento. Como resultado de esta situación se incrementa la baja de la autoestima de estos niños y se torna más inestable el "suelo" sobre el que se constituyen sus frágiles subjetividades.

Quizás, si pudiéramos soportar que las problemáticas que plantea la complejidad de la realidad social posee aristas contradictorias, que actúan en base a conflictos que se les plantea, nos aproximaría a modos de intervención posibles más eficaces. Para que así sea resulta necesario despojar de aquellas connotaciones que aporta el sentido común respecto a conceptos como subjetividad, creatividad y pensamiento crítico. En este sentido, el Psicoanálisis es una de las teorías que más ha profundizado sobre las condiciones que requiere la constitución de la producción simbólica (10) -las que por una cuestión de recorte, no trabajaremos en este escrito-, pero que es necesario tener presente, ya que constituye, quizás, lo más afectado en relación con la constitución del pensamiento relativamente autónomo en los niños marginarizados.

Plantear estas problemáticas de modo dilemático, basado en un pensamiento escéptico, clausura las posibilidades de intervenir en una realidad en continuo movimiento, por lo que, una de sus características esenciales radica en que es susceptible de transformarse por el accionar de los sujetos, a condición de que se formen sujetos críticos, históricos, capaces de objetivarse en sus condiciones de existencia (11). A partir de este tipo de lógicas solamente se arriba a planteos derrotistas que nos despojan de toda posibilidad de intervención en la construcción de subjetividades e identidades un poco más sólidas, cuya condición necesaria, aunque no suficiente, se asienta en el recupero de las raíces socio-históricas del sujeto, raíces capaces de otorgar sentidos a la realidad y a su conducta, para que los individuos recuperen su posibilidad de permanecer "sujetos" de una cultura y así no quedar "sueltos", desligados.

Si el proceso de individuación consiste en un trabajo de diferenciación respecto del Otro, éste no se trata de un proceso lineal y sin conflicto. Las innumerables vicisitudes de la constitución psíquica se caracterizan porque 
lo nuclear que las posibilita es el conflicto que se instala entre lo instituido y lo instituyente, ya que éste puja por imponerse al primero.

La autonomía del pensamiento será tanto más plástica cuanto más firme se haya presentado lo instituido como suelo sobre el cual afirmarse para que la subjetividad se pueda catapultar, transgrediendo/subvirtiendo, liberándose de lo cristalizado de lo instituido.

Las arenas movedizas de la era de la fluidez tornan imposible el salto a la autonomía respecto del Otro Social que requiere el pensamiento creativo. Más bien, promueven adherencias y viscosidad en el Yo del sujeto.

\section{Los niños marginarizados y la Escuela}

Como decíamos en el apartado anterior, el fracaso escolar produce efectos de desubjetivación que profundizan la devastación subjetiva que suelen padecer los niños socialmente marginarizados. La desubjetivación se relaciona con un sentimiento de no poder, con una posición de impotencia de hacer algo para transformar la dolorosa realidad de sus propias vidas, a la vez que el psiquismo del niño se encuentra inhabilitado para simbolizar.

Cuando un niño es excluido del circuito escolar, también corre el riesgo de ser desalojado de la esfera de lo público, sin lo cual no es posible la constitución subjetiva. Los factores que intervienen en dichos procesos de exclusión son complejos y múltiples pero, sin lugar a dudas, la Escuela contribuye notoriamente a conformarlos.

Observábamos en nuestro trabajo en zonas marginales que algunos niños sucumbían a la institución en sus intentos de escolarización, contrariamente a lo afirmado por Alicia Fernández, quien encuadraba a estos niños en los denominados problemas de aprendizaje reactivo, ya que su conducta obedecería a una suerte de rebeldía ante falencias de la enseñanza. Los problemas de aprendizaje con estas características las encontrábamos con cierta frecuencia en niños de sectores más favorecidos socialmente que con los que trabajábamos.

En éstos, notábamos que renunciaban a aprender, identificados con un rasgo asignado por el discurso docente que los rotulaba de "no poder", "no le da la cabeza", "no va a alcanzar". En un trabajo previo (2005), escribimos:

"Los niños con estas características habían ingresado a la Escuela con una cultura que les dificultaba la comprensión "natural" de los lenguajes, códigos y normativas que circulaban en la Escuela. Nuestro trabajo puso de manifiesto que utilizaban modos de comunicarse particulares en los que predominaban, sobre todo en los niños más pequeños, un lenguaje 
del "cuerpo a cuerpo" que, con frecuencia, la Escuela interpretaba como agresión. Un buen ejemplo de lo dicho lo constituyó la anécdota que nos fuera narrada por una supervisora que se interrogaba sobre el no aprender generalizado de los niños marginarizados.

Nos contó que en una oportunidad en que se les estaba repartiendo bizcochos a los niños para acompañar la copa de leche, uno de ellos le tiró a un compañero su bizcocho "por la cabeza". Lo que había llamado su atención es que no reaccionara el niño agredido. La maestra envió al supuesto agresor a la Dirección y cuando éste salió, después de recibir una sanción disciplinaria, la supervisora lo interceptó mientras se dirigía al aula. Le preguntó por qué había hecho eso, a lo que el niño, compungido, respondió: "porque yo sabía que tenía mucho hambre. Él nunca toma nada antes de venir a la escuela y a la noche no come tampoco" (Rosbaco, 2005, p. 31).

En la mayoría de ellos era relevante la particularidad de sus modos de habla, que constituían verdaderos idiolectos. Este elemento diferencial no estaba aislado del conjunto de la cultura de estos niños, sino que era parte de ésta y, junto a otras diferencias que los niños mantenían respecto del capital cultural que reproducía la Escuela, se convertían, en gran medida, en las responsables de sus fracasos escolares. Estos niños habían perdido la confianza en el otro, ya no esperaban nada del adulto, tenían el convencimiento pleno y asumido de su "no poder", pues se sentían inhabilitados por el otro para aprender lo que la currícula escolar exigía y las normativas institucionales, tan naturalizadas por la Escuela, les resultaban incomprensibles. ¡La cultura de la Escuela estaba tan lejos de la suya!" (12).

Los niños explicaban sus fracasos asumiéndolos con culpa; eran niños que anhelaban aprender, sus adultos significativos les habían transmitido el deseo de apropiarse de los objetos culturales, ya que todavía depositaban en la Escuela las esperanzas de promoción social para sus hijos, pero éstos eran diferentes a los otros niños y es por eso que no aprendían. Pensamientos, ideales, representaciones, como los descriptos eran los que circulaban en los comienzos de esta década. Con el tiempo, los padres han ido perdiendo sus esperanzas de que la Escuela incluya a sus hijos y, además, de que en efecto, ésta les otorgue algún beneficio.

A los niños marginarizados con estas características los hemos denominado desnutridos escolares. En un texto de nuestra autoría escribimos:

"El desnutrido escolar no es un niño en el que factores de índole histórico-afectivos, con relaciones tempranas perturbadas hayan comprometido excesivamente su deseo de aprender o su cu- 
riosidad por lo nuevo y diferente, en cuyo caso hablaríamos de problemas de aprendizaje-síntoma".

Entre sus sistemas de pensamiento, creencias, costumbres y valores, y los de la Escuela, se producen cortocircuitos que conducen a estos niños a un repliegue sobre sí mismos. Suele ocurrir que lo que éstos encuentran en la Escuela les sea increíblemente extraño; no hallan nada que opere como nexo entre lo que traen de su mundo privado -lo familiar- y lo público, extraño, cada vez más desconocido. Todo lo cual les dificulta enormemente las posibilidades identificatorias a objetos de la cultura tan extraños a su vida cotidiana.

Nada de lo de ellos puede hacer de puente con esa realidad en la que no les es factible encontrar objetos con los cuales identificarse. El desencuentro entre los pequeños sujetos y los docentes se produce precisamente en este punto. Esto genera, involuntariamente y sin la menor animadversión, una "violencia simbólica secundaria excesiva sobre los niños, con consecuencias severas para el psiquismo infantil" (Rosbaco, 2007, p. 53).

Quedar desafiliados del sistema educativo es quedar a la deriva, social y psíquicamente, para aquellos niños que lo único que tienen para permanecer dentro del sistema es la posibilidad que les brinda la Escuela, y de este modo, contar con la posibilidad de proseguir constituyéndose psíquicamente, ya que la esfera privada del ámbito familiar no es suficiente ¡Está en juego el destino psíquico y muchas veces físico de estos niños!

Por todo lo expuesto, hoy más que nunca es importantísimo que el referente docente conserve la distancia generacional y la autoridad que otorga la palabra para subjetivar a los pequeños sujetos, haciendo hincapié en un trabajo que abra a la posibilidad de imaginar otros mundos posibles, que ayude a instaurar en medio del desierto un oasis, un proyecto de vida.

No se trata de pensar a la Escuela con fines adaptativos pasivos, sino constitutivos del sujeto y de su pensamiento creativo. En la contradicción que encierra el par instituyente/instituido, el docente puede crear condiciones para promover el pensamiento crítico, la creatividad, reflexivo, en niños que, muchas veces, es la Escuela la que puede convertirse en la única posibilidad que éstos tienen como vía de acceso a los códigos de la esfera de lo público.

\section{En la esfera de lo público: la Escuela}

En los últimos tiempos hemos observado con preocupación el alejamiento pronunciado que tienen los habitantes de los barrios marginales respecto de la esfera pública. 
Al descenso abrupto que han tenido estos trabajadores desocupados -devenidos en muchos casos en cartoneros-, se le suma el aislamiento físico de los asentamientos, cada vez más acentuado, sea por la construcción de caminos para el transporte pesado, sea con muros que los separan del resto del conjunto social. Nos preguntamos sobre la incidencia de esta fractura social y discriminación en la constitución psíquica de las nuevas generaciones.

Ángel Fiasché (2005) relaciona las condiciones espaciales con la enfermedad mental. Para este autor, con el que coincidimos plenamente, el espacio real se introyecta, lo que incide en los modos de relación social. Por ejemplo, si se vive hacinado, es difícil establecer la distancia óptima requerida en un vínculo social. Es curioso cómo los niños se quejan con frecuencia que no tienen espacios para ellos, que no pueden preservar sus juguetes o cuadernos en espacios seguros que no estén al alcance de los hermanos menores. Lo manifiestan con angustia, del mismo modo que viven aterrados por el peligro que les significan las tormentas, granizos, que arrancan fácilmente los techos de sus precarias viviendas.

En una oportunidad en que las madres se referían a la inseguridad con que viven, una exclamó: "Yo vivo entre dos casas de "narcos". Por suerte mi casa es de ladrillos, así que cuando se arman las balaceras porque vienen los pobrecitos sin plata y como son drogadictos le piden, le ruegan que "les tire algo", pero nada, lo que le contesta el hombre es: "cuando tengas plata, veni", entonces ellos sacan sus armas o piedras y le empiezan a tirar a la casa, de bronca lo hacen y por desesperación, ¿no viste cómo está llena de agujeros? -le pregunta a una compañera-. Ahora, yo digo, mi casa es de ladrillos, dentro de todo mis hijos están algo protegidos, pero las demás que están cerca de donde vivo tienen casillas, ¿con qué miedo viven esas madres que saben que una bala es tan fácil que atraviese las paredes? Siempre pienso en esto... los chicos... corren tanto peligro... viven asustados y... ¿cómo hacen las madres?" (13).

¿Qué decir, entonces, de las vías que separan a las clases sociales entre los que viven "de este lado de la vía" y los que viven "detrás de la vía" -como suelen diferenciar los docentes a sus alumnos-, de los que viven detrás de los muros?

¿Cuál es el impacto en la subjetividad que produce el alejamiento de la esfera pública, asociado al pánico con el que están creciendo los niños?

Ésta constituye una de las preguntas fundamentales que nos hacemos en la actualidad por el avance de la expulsión, más visible espacialmente que tiempo atrás, a lo que se suma el estado de miedo permanente que acompaña el transcurrir de la vida de estos sujetos. 
Lo que estamos observando es que este aislamiento ha llevado a que inclusive los adultos tengan temor de los espacios de la esfera pública. Así por ejemplo, ocurrió a una mamá del grupo de madres piqueteras con el que nos encontrábamos trabajando, en ocasión de tener que realizar un trámite en una dependencia municipal de Rosario (ella vivía en una cercana ciudad pequeña), se vio confrontada a su incomprensión de los códigos con que se organizan las relaciones entre empleados y usuarios, de sus modos de expresarse, de la distribución espacial de las oficinas.

Tras reiterados intentos por averiguar adónde tenía que dirigirse para efectuar el trámite que necesitaba, entró en un estado de desorganización y angustia al no comprender las indicaciones "hechas a la ligera" por empleados sobrecargados de trabajo. Desesperada, salió a la calle y la cruzó. Un automóvil estuvo a punto de atropellarla. El hombre, enojado por la imprudencia de la mujer que cruzó la calle sin mirar, se bajó para insultarla. Era tal su llanto desgarrador y su estado de pánico, que el buen hombre se condolió y la llevó hasta su domicilio.

Esta señora, cabe aclarar, era una de las dirigentes piqueteras que con frecuencia participaba de los cortes de ruta y de los reclamos que solían realizar frente a la Municipalidad de la localidad en que vivía. En la arenga política no tenía temor, luchaba por sus derechos como ciudadana, por el de sus hijos y por una mayor justicia social.

Este episodio es elocuente del desconocimiento que poseen los marginarizados de los modos de desenvolverse en la esfera pública cuando se trata de algo personal que no cuenta con el respaldo de las organizaciones políticas, que sí están presentes y los organizan en sus reclamos. Lo mismo ocurre cuando tienen que solicitar lo que por derecho les corresponde en áreas vinculadas a salud, educación, etc.

Cuando hemos preguntado por qué no asisten a las reuniones de madres a las que convocan los docentes de sus hijos, suelen responder que no saben qué hacer con las indicaciones que les dan. La frase "no entiendo cuando la maestra me dice que..." es una de las más comunes con las que argumentan los motivos de su ausencia a las reuniones de padres.

El trabajo que hemos realizado el año pasado, sumado a lo que venimos observando en los niños desde hace algunos años, nos ha llevado a resaltar la importancia de la Escuela, poseedora de las "llaves del código del capital cultural" de la sociedad (Bourdieu, 1991). Producir el alejamiento de la esfera pública en sujetos no insertos en la producción con políticas expulsivas, es una de las tantas formas de aniquilar la subjetividad de los sujetos marginarizados; probablemente la que más ayude a exterminarlos. 
Es por esto, que más allá de que la Escuela conserve los rasgos para lo cual fue creada en la Modernidad, cuya función principal consiste en reproducir un perfil subjetivo funcional a la reproducción del sistema social, debemos reconsiderar sus posibilidades. No existe en la esfera pública ninguna oferta para los niños marginarizados que disponga del capital cultural acumulado del conjunto social al alcance de éstos como la sistematización que de éste tiene la Escuela.

Decíamos en un comienzo que la escuela nos plantea una contradicción que hay que sostener: a la vez que reproduce, hay docentes que demandan un cambio en sus prácticas, con la incorporación de ideas basadas en la educación popular, y a éstos apostamos. Es decir, no pretendemos con nuestras prácticas cambiar el sistema educativo en el que se inserta la Escuela, para lo cual habría que encararlo, organizadamente, desde otros lugares. Lo que sí podemos hacer es colaborar desde nuestras disciplinas a sostener a los docentes para que puedan ejercer sus prácticas subjetivantes (teniendo en cuenta que el centro de dichas prácticas es enseñar el capital cultural) incorporando los aportes e ideología que subyace a la educación popular.

Deseamos hacer una salvedad. Hoy existen en nuestro país y en otros países latinoamericanos experiencias inéditas de nuevos modos organizacionales realizados por sectores populares: las fábricas recuperadas, los cambios operados en muchas comunidades, producto de la intervención de movimientos sociales, haciendo resistencia al modelo socio-político imperante, han sentado las bases para nuevas experiencias tendientes a la transformación social.

Uno de los objetivos que dichos movimientos se propone es la creación de escuelas en el ámbito en el que actúan, con el reclamo de que los docentes sean miembros pertenecientes a los movimientos sociales. De este modo, la Escuela ya no sería reproductora de un sistema opresor, sino que los lazos solidarios y horizontales serían los que se promoverían en los niños en la búsqueda de una "atmósfera" solidaria que incidiría en la subjetividad de éstos.

Consideramos que éstas son las nuevas Escuelas a las que hay que aspirar, siempre y cuando algún movimiento social haya cobrado fuerza como para instalar en el lugar donde opera una escuela con un perfil superador al de la escuela tradicional, capaz de incidir en la gestación de subjetividades solidarias. Las múltiples experiencias que se están gestando en toda América Latina auguran transformaciones sociales posibles con escuelas de este tenor. 
La problemática concerniente a la subjetivación y a la alfabetización con respecto a los niños marginarizados nos obliga a posicionarnos respecto de la Escuela tradicional de un modo diferente cuando los movimientos sociales todavía no han cobrado la fuerza suficiente como para instalar sus propias escuelas en los barrios.

Creemos que, ante la ausencia de referentes culturales y de adultos con quiebre de ideales y altas cuotas de sufrimiento que poco pueden donar, la Escuela es el único medio que éstos tienen para acceder a la esfera de lo público. Lo público da la posibilidad de simbolizar a través de ideales vinculados a objetos socialmente valorados.

\section{Pequeñas propuestas que subjetivan a los "nadies"}

"El desafío del educador es hacer deseable los objetos de la cultura" - Jean Marie Gillig-

Por todo lo expuesto, es que damos relevancia a ciertas sugerencias viables para las prácticas docentes desde los aportes del Psicoanálisis, tendientes a la incorporación de los códigos de la Escuela, del fomento de la responsabilidad con que se asume un trabajo que se puede hacer visible para el conjunto de los actores de la Escuela, quienes devolverán múltiples miradas, manifestando de este modo una "escucha" atenta del otro-niño, que tiene una existencia, que sufre, se alegra, juega, siente placer y displacer por lo que hace o le pasa. Todo lo contrario de lo que ocurre hoy en la esfera pública "que mata con la indiferencia".

La mirada que devuelve el Otro Social es lo que nos hace tener el sentimiento de existencia. De ahí que, cuando más indiferencia o desestimación devuelva el Otro Social de los reclamos de necesidades concretas y del sufrimiento psíquico de los sujetos, crecerá la angustia de anonimato, de inexistencia, y las fantasías arcaicas de abandono retornarán desde una exterioridad al sujeto, convirtiéndolas en algo del orden de lo siniestro (14).

Vaya el siguiente cuento elaborado por un grupo de niños de ocho años de una escuela marginal para comprender su sufrimiento, el sentimiento de encerrona en el mundo que les ha tocado en suerte, la autopercepción que tienen de sí mismos -que siempre se relaciona con la mirada que devuelve el Otro Social- y la naturalización de la muerte prematura, en este caso, producida por la misma naturaleza, ¡hasta ese grado llega la naturalización de los que les ocurre!: 


\section{Cuento "El Diablo Malo"}

"Un diablo era muy malo, y la novia era pior, y el hijo era pior.

Un día fueron a caminar y la gente dijo: ¡Ah, ah!, jun diablo! Y se fueron a otra ciudad y fueron a su hogar. Y pensaron por qué somos tan malos. $Y$ la novia le dijo porque somos muy rojos y tenemos cuernos y colmillos, $y$ dijeron ¿por qué no nos podemos mudar?

Y fueron a otra ciudad, que está sola en un campo y ahí tenían vacas, de todo, pero les gustaban las vacas y los cerdos porque era la comida preferida de los diablos y también les gustaba el pasto porque se quedaban dormidos.

Pero estaba lloviendo, pero no sabían que la lluvia era el peor enemigo de los diablos, porque la lluvia los derretía".

Las prácticas docentes subjetivantes pueden transformar a un sujeto con una adaptación pasiva, como el que se plantea en el ejemplo dado, en un sujeto con un posicionamiento activo. El ejemplo con el que ilustramos este pasaje corresponde a compañeros de los que narraron el primer cuento, luego de la intervención de nuestros alumnos sobre narrativas que subjetivan, basadas en las propuestas del programa de cátedra. Los niños, entusiasmados, lograron escribir este cuento con ayuda del coordinador:

"tocamos en el parque, tenemos el gorrito y nos tiran monedas, y después vamos al Parque España para hacer el día del niño.

Tocamos en las colectividades donde bailó la chica brasilera.

Después nos subimos a la tarima a cantar.

El perro estaba tocando con la lengua".

Se trata de un posicionamiento subjetivo de los niños que experimentaron la alegría de la murga; divirtiéndose, pudieron obtener monedas; salir del ámbito de lo que es "más de lo mismo" -familia, barrio- y, mediante la función de paseo experimentada (Rodulfo, 1985), disfrutaron un "afuera" público/simbólico -el Monumento a la Bandera-; recuperaron el estatuto de niño (debemos aclarar que fue la única vez, en nuestra larga trayectoria, que apareció una alusión al estatuto de niño); "la chica brasilera" implica el acercamiento a lo extranjero/lo novedoso con el que tuvieron un contacto placentero; en la tarima fueron mirados por muchos que centraron su atención en lo que hacían, acción acompañada del retorno valorativo de dichas miradas; y hasta el perro -no sólo los que se sienten ser "nadies"participó".

La Escuela debiera promover que los docentes ejerzan prácticas subjetivantes tendientes al pasaje del sentimiento de ser "nadie" al senti- 
miento de ser "alguien". Ése es el verdadero desafío en lo que incumbe a la subjetividad que puede y debe realizar el docente.

Desde este punto de vista es importante transformar las producciones infantiles privadas en objetos culturales y/o públicos, es decir, con valor para la mirada de los otros, pares y docentes-adultos representantes del Otro Social. Hay experiencias realizadas en escuelas, en que las producciones de los niños cobran valor de mercado, ya que éstos venden los productos que elaboran; en otras, elaboran objetos culturales como periódicos con noticias de lo que ocurre en la escuela -una seño queda embarazada, mientras otra se casa; un alumno de otra escuela, M., comenzó a concurir a ésta; el compañero $\mathrm{S}$. de segundo grado se enfermó; otro tuvo un hermanito- (Neira, 2003).

Que los niños narren con una escritura en manuscrito; que los docentes la tipeen en computadoras con un formato que se asemeje a la escritura en letra de molde -como las de un libro, objeto cultural-; que les sea publicado en imprenta con el nombre del autor; que les sean devueltas las producciones "en estado público" (expuestas en las pizarras del patio, difundidas por alguna FM a la que tenga acceso la escuela), constituyen los pasos sucesivos de un proceso de transformación de lo privado a lo público ¡que tantos años le llevó conseguir a la humanidad!; cobran un valor sin igual, ya que estos actos hablan de un otro adulto que "escucha" y devuelve, como representante social, un objeto que era privado en uno que fue convertido en un objeto de la cultura. Se trata de recuperar un "alguien" allí donde "un "nadie" produjo un objeto privado, al que se le devuelve su objeto transformado en un objeto de la cultura/público. En este acto hay un reconocimiento de la existencia del ser del niño con baja autoestima por un representante del Otro Social, ¿primeras experiencias de reconocimiento de la existencia en la esfera pública?

El sentimiento de sentirse autor de una producción implica el pasaje de un sujeto pasivo a uno activo, que asume un posicionamiento responsable frente a los otros, ¿en qué momento de la historia de estos niños habrán sentido el peso de la responsabilidad?, no por el cumplimiento de trabajos que no debería efectuar un niño ni por inversión de roles de cuando se tienen que hacer cargo del procuro de alimentos o dinero para sus adultos significativos o hermanos menores, sino esa responsabilidad que implica la decisión de compromiso ante un otro, en un acto que pone de manifiesto el deseo de ser alguien para ese otro. Éste es el aditamento subjetivante que poseen estas propuestas.

La responsabilidad es siempre social, se asume frente a los otros, de modo consciente, mediante una elección por medio de la cual el sujeto 
selecciona, en un acto de discriminación, lo que desea hacer público de aquello que desea reservarse para su fuero íntimo. Cuando un sujeto realiza una producción para otros, convierte sus objetos internos en públicos, relacionados con objetos socialmente valorados, simbólicos. Lo que no tiene parangón a la hora de evaluar el impacto que produce en la subjetividad propia y en la de los otros-semejantes-pares, que le devuelven una mirada valorativa en la dimensión de lo social.

Si el proceso de individuación consiste en la separación/discriminación del Otro, este acto de elección responsable tiene una ponderación especial, ya que empuja al sujeto a efectuar un acto de discriminación al seleccionar y anticipar -operaciones del pensamiento autónomo- aquello que se quiere mostrar.

Este pasaje de lo privado a lo público, asumiendo responsabilidad frente a los otros, levanta la autoestima a la vez que permite la identificación a modalidades de relación y comunicación que hacen a la inclusión social.

Recordemos que el Yo se constituye y se potencia a través de las identificaciones que realiza el sujeto. La subjetividad, como esbozamos más arriba, está conformada por dos aspectos: uno que hace a las identificaciones que el sujeto ha construido en base a lo instituido de la cultura, que encontró organizado al momento de nacer; pero existe otro aspecto que hace al mismo proceso de construcción de la subjetividad, que se relaciona con aspectos instituyentes, creativos, de la subjetividad. Entonces, de lo que se trata en la escuela, es de pensar estos espacios instituyentes que permitan recuperar a los niños excluidos del sistema.

El pensamiento creativo tiene un cariz transgresor de lo instituido, lo agujerea, resistiéndosele, lo que lo torna original con la marca del nombre propio. Para que éste se constituya, el niño tienen que experimentar conductas espontáneas, propias, creativas, al interior de un campo deseante del Otro.

Cuando el referente docente limita las potencialidades del sujeto diagnosticando "que no le va a dar la cabeza" o "no va a alcanzar", no lo autoriza a pensar. Sin el menor atisbo de sospecha, el adulto ejerce una prohibición inhabilitante.

¡No se desea curiosear ni buscar el conocimiento si no se está muy seguro de que lo que se sabe es válido para el otro, si el sujeto no siente que él mismo tiene valor para ese otro! Es por eso, que la indiferencia es el peor enemigo del pensamiento creativo.

Cuando se rotula, el niño puede cristalizarse en ese lugar de "no poder", asumiendo el lugar asignado, que, desde luego, puede coincidir o no, con el que le asignó el grupo de pertenencia. 
Suele ocurrir que se confundan los diagnósticos y se considere que la escuela especial es beneficiosa para determinados niños marginarizados por su dificultad en el desempeño en la escuela común. Nosotros consideramos que, en estos casos, la escuela especial no puede ayudarlos, porque la problemática que padecen tiene otros orígenes que aquéllos de los niños para los cuales fueron construidas estas escuelas.

Esos niños quedan expuestos a asumir como propia una imagen asignada: actuarán, pensarán y sentirán, en consecuencia. La literatura psicoanalítica al respecto es abundante.

Recordamos tristemente a G., hijo de un padre que fuera obrero fabril, hoy desocupado. Nos fue derivado para psicoterapia con un diagnóstico que comprometía severamente su intelecto. Tanto su madre como él lucharon durante años para que pudiera permanecer en la escuela común. Actitud que apoyamos incondicionalmente.

Al cabo de cinco años de insistir en la escuela que G. "podía" permanecer en una escuela común, que no era un niño con una deficiencia mental sino que tenía otro tipo de problemáticas que estábamos tratando, G. vino a su tratamiento con una expresión de tristeza en su rostro que reflejaba una intensa angustia. Este niño, diagnosticado como deficiente mental durante tantos años, nos contó que estaba harto de que su maestra le tuviera lástima.

- ¿Por qué creés que te tiene lástima?

- En el recreo me da monedas para que me compre algo de comer. Yo le dije que yo no era un estómago.

- ¿Y qué sos vos?

- ¡Yo soy una persona! (SIC) (15)

Dos semanas después, la madre nos anunció que estaba gestionando la deri vación de G. a una escuela especial.

- "¡Ya me cansé de pelear, no puedo más!” (nos dijo llorando).

A fin de año, G. abandonó su tratamiento. Seis meses más tarde vino con su madre a visitarnos. Se lo veía contento, o al menos tranquilo; a su mamá también. Nos contaron que G. se destacaba mucho de sus compañeros en el taller de carpintería. Ahí todos valoraban sus producciones, lo que evidentemente alegraba al niño. Mientras observábamos el rostro alegre de G., pensábamos que seguramente se lo veía tranquilo a costa de no seguir "peleándola" para desarrollar sus potencialidades de pensamiento. Era verdad que su desarrollo era más lento y lineal que el de otros niños; era verdad que en la escuela común sufría mucho porque "no le tenían paciencia" -como dijo un día en clara alusión a una expresión del 
conocido personaje El Chavo-; era verdad que en esta escuela sí le tenían paciencia.

Nos preguntamos: ¿qué hubiera sido preferible para G.: un costo alto en sufrimiento para no ser discriminado, siempre bajo el yugo del "no podrás" o el altísimo costo de su desubjetivación, lo que efectivamente ocurrió con el paso del tiempo?

En los niños estigmatizados, la suerte de su destino, entendido éste como construcción de un proyecto de vida, ha sido echada. La mayoría de la veces, cual profecía cumplida, pueden quedar replegados en su no poder.

Los efectos de las prácticas docentes -se trate de una escuela tradicional o, cuando es posible, de las escuelas que instalan los movimientos sociales en movimientos de resistencia a lo instituido- son los puntos de anclaje y entrada a la esfera pública, indispensables para la constitución del psiquismo.

En ambas, aunque con lazos sociales diametralmente opuestos, es necesaria la presencia de un adulto-referente de la cultura, capaz de promover el pensamiento crítico, incentivando la confrontación de ideas entre pares, y la contra-argumentación a que se lo compele al sujeto, desde una ley que le es externa, que el docente debe regular.

De la idea sin forma que surge de lo íntimo/privado a un pensamiento crítico que es expuesto socialmente. Entre la familia/barrio y el "afuera" público se juega el destino psíquico de los niños marginarizados: las prácticas docentes tienen en sus manos la posibilidad de contribuir a dicho pasaje ¡y no es un imposible!, ¡se puede! (16).

\section{Notas Bibliográficas}

(1) Hoy se ha instalado en nuestra sociedad la discusión sobre la posibilidad de bajar los años de imputabilidad de menores. Lo curioso es que a la vez que la ciencia considera que la franja etaria de la adolescencia ha ampliado sus márgenes a los que hasta hace poco eran considerados adultos, ¿cuestión evolutiva biológica o consecuencia de la falta de trabajo?, paradójicamente se pretende "cargar" sobre los adolescentes la "culpa" y responsabilidad de sus conductas ocasionadas por las mismas políticas económicas que los culpabilizan. Entendemos que estos niños-adolescentes son las víctimas de un sistema implacablemente expulsivo.

(2) Cabe aclarar que las políticas económicas han sufrido un cambio desde el neoliberalismo al neo-desarrollismo actual, con un cambio en la función del Estado que se pretende más centralizador, pese a lo cual, no notamos que la escuela, por ejemplo, sea menos expulsiva que tiempo atrás. Más bien 
ocurre a menudo, encontrarnos en las entrevistas realizadas a madres, que éstas manifiesten su total falta de expectativas de lo que se puede esperar de la escuela. Ha aumentado considerablemente el porcentaje de niños que no asisten a la escuela porque "para qué lo voy a mandar si ya sé que le va a pasar lo mismo que al más grande: primero va a repetir y después lo van a terminar mandando a casa de nuevo". (Entrevista a una mamá, correspondiente al proyecto en curso "El grito y la marca. Procesos de desubjetivación en niños con madres implicadas en el reclamo social activo").

(3) Concepto que deriva del verbo marginar que refiere a una acción que se ejerce sobre alguien, ya que los expulsados del sistema no se han marginado por cuenta propia. Se acentúa el carácter involuntario de dicha condición.

(4) En alusión a la letra de una canción dedicada a los albañiles, titulada "Construcción". Compuesta por Chico Buarque. Cada estrofa termina, respectivamente, diciendo:

- "Murió a contramano interrumpiendo el tráfico"; "murió a contramano interrumpiendo al público", "murió a contramano interrumpiendo al semejante"; "murió a contramano interrumpiendo el sábado".

(5) Una compañera de trabajo comentaba: "Hoy se les pide pensamiento crítico, se festeja la rebeldía, por ejemplo, cuando alguien se tiñe el cabello de verde". De esa rebeldía es de la que no vamos a hablar ni propiciar. Es una rebeldía que está llevando a muchos niños y adolescentes, que convencidos de sus discursos propios, corren el riesgo de sumarse a las actuales patologías del vacío que padecen algunas subjetividades de esta época (remitimos a Galende, 1994).

(6) Lacan define lo real a lo que no tiene sentido de la realidad, ya que no produce inscripción en el sujeto por falta de palabra, aunque éste puede sufrir sus efectos.

(7) En este punto hay que hacer la salvedad que nos estamos refiriendo a los barrios o comunidades que se encuentran prácticamente en el grado de indigencia, que han quedado literalmente a la intemperie respecto de la función de protección que le cabe al Estado. Con lo cual, la Escuela pasa a ser, muchas veces, la única oportunidad que tienen para entrar a la esfera de lo público. Muy distinto ocurre con los niños que crecen en una "atmósfera" (Zibecchi, 2008) generada en un ámbito determinado, producto del trabajo transformador de movimientos sociales como Los Sin Tierra, movimientos sociales de La Matanza, etc., en cuyo caso, todos estos movimientos han luchado por tener escuelas propias.

(8) En octubre de 2008 se llevó a cabo en la ciudad de Paraná, propiciado y organizado por el gremio docente, un congreso de este tenor, que contó con un caudaloso público de docentes. Nos referimos al "II Encuentro Latinoamericano de Educadores Populares por la Alfabetización", en el que participaron prestigiosos especialistas en Educación Popular, de quienes los docentes aspiraban a tomar ideas para renovar sus prácticas en el aula. Es elocuente el logos del evento tomado de un texto de Galeano, que consiste en una América 
Latina "patas para arriba". Hay muchas experiencias que se están llevando a cabo con la incorporación de dispositivos diferentes a los tradicionales. Por ejemplo, en Rosario funciona una escuela-orquesta en la escuela Luisa Mora de Olguín" № 1.027 del Barrio Ludueña, en una escuela de Concepción del Uruguay (Entre Ríos) han introducido un taller de murga.

(9) Los enunciados de fundamento (Aulagnier, 1979) son portadores de certezas incuestionables sobre los que se funda el psiquismo.

(10) "Se considera producción simbólica a la actividad representacional sustitutiva, resultado de la complejización del aparato psíquico que supone la respectiva división en instancias. Esta actividad sustitutiva permite diferir la fantasía que caracteriza al proceso primario para depositarla parcialmente en representaciones sociales de características simbólicas" (Bo, 2006). La autora refiere que esta producción tiene la posibilidad de crear objetos, cuyas características consisten en que son sociales, simbólicos y públicos.

(11) La objetivación de las condiciones de existencia como condición para que el sujeto tome conciencia de "su lugar en el mundo", en relación con los que se encuentran en igualdad de condiciones como oprimidos y con los que los oprimen, requiere de la recuperación de un sujeto con historia, ya que sólo a través de ésta, el sujeto dispondrá de elementos que le permitan interpretar y otorgar sentidos a la realidad actual. Razón por la cual, los discursos en boga que reniegan de las raíces históricas, en la búsqueda de algún supuesto potencial susceptible de ser detectado en el niño para, desde éste, incluirlo en la Escuela, nos parece totalmente funcional a los requerimientos del sistema actual, ya que en el mismo acto de reconocimiento de ese supuesto potencial, se despoja al niño de su posibilidad de reconocimiento de su identidad en una estructura social que lo oprime, a la vez que contribuye a acentuar su ya fragmentado psiquismo.

(12) Es notable como el "no poder" de los niños marginarizados con las características de desimbolización, sumado a la falta de confianza en el referente-adultodocente, fueron fenómenos que no eran visualizados por los docentes ni por los profesionales afines a la educación a mediados de los años '90. Recién en la década del 2000 se pudo comprender este fenómeno que hoy en día se encuentra tan naturalizado que hace obstáculo a su reflexión.

(13) Comentario de una mamá en un taller realizado para al proyecto de investigación en curso "El grito y la marca. Procesos de desubjetivación en niños con madres implicadas en el reclamo social activo".

(14) Lo siniestro se relaciona con algo de lo familiar/conocido/fantaseado (en este caso el temor al abandono que tienen los niños que nacen sin capacidad de sobrevivir sin un adulto que lo asista en sus necesidades) que es reprimido y puede, en algún momento, retornar desde el exterior.

(15) Sería casi imposible que un niño con una deficiencia mental de consideración pudiera enunciar esta respuesta. Supusimos que se trataba de un diagnóstico equivocado y por eso insistimos en que se mantuviera incluido en una escuela común. 
(16) En el presente trabajo se utilizó letra cursiva para destacar los términos conceptuales; se escribió con mayúsculas la palabra escuela cuando se hizo referencia a su sentido general, a la vez que se utilizó minúscula en las ocasiones en que la palabra hizo referencia a alguna escuela en particular.

\section{Referencias Bibliográficas}

- Aulagnier, P. (1979) La violencia de la interpretación. Buenos Aires, Amorrortu.

- Bo, T. (2006) “Intervenciones”, en Wettengel, L. y Prol, G. Tratamientos de los problemas de aprendizaje. Buenos Aires, Noveduc.

- Bourdieu, P. (1991) La distinción. España, Taurus.

- Bourdieu, P. (1996) Cosas Dichas. España, Gedisa.

- Dufour, R-D. (2007) El arte de reducir cabezas. Buenos Aires, Paidós.

- Fiasché, Á. (2005) Hacia una psicopatología de la pobreza. Buenos Aires, Madres de Plaza de Mayo.

- Galende, E. (1994) "Modernidad, individuación y manicomios", en Saidón, O. y Troianovski, P. Políticas en salud Mental. Buenos Aires, Lugar.

- Gillig, J. M. (2000) El cuento en pedagogía y en reeducación. Primera edición 1999. México, EFE.

- Käes, R. (1996) "Introducción al concepto de transmisión psíquica en el pensamiento de Freud", en Káes, R., Flaimberg, H. et al. Transmisión de la vida psíquica entre generaciones. Buenos Aires, Amorrortu.

- Le Breton, D. (2007) El adiós al cuerpo. México, La Cifra.

- Neira, A. (2003) Otra mirada de los valores morales. Buenos Aires, Paidós.

- Rodulfo, R. y Punta, M. (1985) Clínica con niños y adolescentes. Buenos Aires, Paidós.

- Rosbaco, I. (2002) "El deseo de aprender: un antídoto al fracaso escolar", en Carreras, M., Gluz, N. et al. La escuela: una segunda oportunidad frente a la exclusión. Colección Psicología y Educación. Ensayos y Experiencias. Buenos Aires, Novedades Educativas.

- Rosbaco, I. (2004) Impacto de las políticas socioeconómicas en los procesos de desubjetivación en niños de contextos sociales vulnerables. Primera edición en 2003. Villa María, Biblioteca Popular Eduardo Requena.

- Rosbaco, I. (2005) “En el camino de la desubjetivación: el desnutrido escolar". Cuaderno 3 del FEIA. Buenos Aires.

- Rosbaco, I. (2007) El desnutrido escolar. Dificultades de aprendizaje en los niños de contextos de pobreza urbana. Primera edición en 2000. Rosario, Homo Sapiens.

- Rosbaco, I. (2008) "La escuela, lo público, lo popular. Patas para arriba", en II Encuentro de Educadores Latinoamericanos, "La escuela, lo público, lo popular". Paraná. 
- Yanín, B. (2001) "La infancia, la constitución de la subjetividad y la crisis ética". Extraido de página WEB.

- Zibechi, R. (2008) "Los movimientos sociales como espacios educativos". La Capital. 